\title{
INCREASE OF HIGH LOAD LIMIT IN A GASOLINE HCCI ENGINE
}

\author{
Jacek Hunicz, Paweł Kordos, Michał Gęca \\ Lublin University of Technology \\ Institute of Transport, Combustion Engines and Ecology \\ Nadbystrzycka 36, 20-618 Lublin, Poland \\ tel.: +4881 5384261,fax: +48 815384258 \\ e-mail: j.hunicz@pollub.pl,p.kordos@pollub.pl,michal.geca@pollub.pl
}

\begin{abstract}
Engine operation in HCCI mode allows for improvement of thermal efficiency and substantial reduction NOX emission. The most production feasible solution for gasoline HCCI engine is application of exhaust gas trapping using a negative valve overlap. This technique increases thermal energy of a mixture, thus allowing for auto-ignition at moderate compression ratios. However, high exhaust gas re-circulation rate decreases volumetric efficiency. As a result, achievable engine loads are also reduced. Supercharging can be applied in order to improve volumetric efficiency and extend high load limit. However, increase of amount of intake air can lead to reduction of start of compression temperature via decrease of residuals in a mixture. In order achieve HCCI mode of combustion, temperature of start of compression must be kept within narrow limits.

In this study experimental and modeling investigations were presented. Experiments were carried out using single cylinder research engine. The engine was equipped with fully variable valvetrain and direct gasoline injection. Application of mechanical boosting allowed for widening achievable load range in HCCI mode of operation. Numerical calculations allowed for determination of admissible valvetrain settings and intake pressure, which guarantee proper temperature of start of compression.
\end{abstract}

Keywords: HCCI engine, negative valve overlap, high load limit, mechanical boost

\section{Introduction}

The main advantage of homogeneous charge compression ignition (HCCI) combustion systems versus spark ignition and diesel engines is the substantial reduction of cylinder-out $\mathrm{NO}_{\mathrm{X}}$ emission. Additionally, fast heat release rate allows for an increase of thermal efficiency in comparison to spark ignition engines [5].

In order to obtain the auto-ignition temperature, it is necessary to provide additional energy to the in-cylinder load. This can be achieved in a several ways. In early experiments on this combustion system intake air preheating was widely used, often combined with elevated compression ratios [3]. However, this technique is not applicable in production automotive engines. The most production viable solution for introducing additional energy into the cylinder is internal exhaust gas re-circulation (EGR) utilizing negative valve overlap (NVO), however this technique application is limited to low and medium loads [7].

Substantial dilution of the in-cylinder load by re-circulated exhaust provides reduction of volumetric efficiency, and therefore limits high load boundary in HCCI combustion mode. Moreover, engine operation in HCCI mode at loads above $0.5 \mathrm{MPa}$ of indicated mean effective pressure (IMEP) is associated with high mechanical and thermal loads of combustion chamber parts [6]. Mechanical loads are the result of relatively high pressure rise rate. The thermal loads are increased by higher mean in-cylinder temperatures due to the large amount of re-circulated exhaust. In case of negative valves overlap, in-cylinder load is compressed twice during a single engine cycle.

Supercharging of the HCCI engine allows for increase of the permissible engine load if limitations come from insufficient amount of the intake air [4]. Increase of intake pressure allows 
for application of lower EGR rates. However, fast heat release and large amounts of fuel at higher engine loads can result with excessive pressure rate rise. According to Gaynor et al. [1] and Yap et al. [8] application of boost and increase of in cylinder charge mass allows substantial reduction of $\mathrm{NO}_{\mathrm{X}}$ emission and pressure rate rise simultaneously. In contrast, Scaringe, Wildman an Cheng $[4,6]$ reported that in order to reduce pressure rise rate intake pressure should be minimized.

The aim of this study was estimation of influence of boost pressure on HCCI engine working processes. In order to achieve auto-ignition in-cylinder temperature was elevated with the use of internal EGR obtained via the NVO technique. Research engine was fuelled with gasoline with the use of direct injection. An analysis of attainable increase of maximum engine load via boost application was performed on the base of measurement data and supported by engine cycle modeling.

\section{Experimental setup}

The research was carried out using a SB 3.5 single cylinder research engine. Main engine parameters are specified in Tab. 1.

Tab. 1. Research engine SB 3.5 specifications

\begin{tabular}{|l|l|}
\hline Displaced volume & $498.5 \mathrm{~cm}^{3}$ \\
\hline Bore & $84 \mathrm{~mm}$ \\
\hline Stroke & $90 \mathrm{~mm}$ \\
\hline Compression ratio & $11.7: 1$ \\
\hline Number of valves & 2 \\
\hline Intake cam profile & $9.4 \mathrm{~mm}, 235^{\circ} \mathrm{CA}$ \\
\hline Intake valve lift & $2.4 \ldots 9.4 \mathrm{~mm}$ \\
\hline Exhaust cam profile & $9.2 \mathrm{~mm}, 235^{\circ} \mathrm{CA}$ \\
\hline Exhaust valve lift & $2.2 \ldots 9.2 \mathrm{~mm}$ \\
\hline Fuel injector & Solenoid, swirl type \\
\hline
\end{tabular}

All valvetrain parameters could be changed independently for the intake and exhaust valves during engine operation. Variable valve lift was achieved with the use of a hydraulic device.

The research engine had a bowl shaped combustion chamber located in the engine head. The piston face was protruding on its perimeter and approached the cylinder head closely at TDC, which generated some amount of squish. A direct fuel injector was located in the engine head on the opposite side of the spark plug with $38^{\circ}$ of axial inclination in relation to the cylinder axis. Although, such a configuration of the combustion chamber was not a proper arrangement for spark ignited combustion of a stratified charge, in CAI operation mode it was indifferent. The design of the combustion chamber was described in details in ref. [2].

During the experiments a Bosch solenoid injector type HDEV was used. It was an inwardly opening pressure-swirl injector providing cone fuel stream with angle of approx. $67^{\circ}$. Low- and high-pressure fuel pumps were electrically driven in order to obtain constant pressure independent of engine speed. The desired fuel pressure was set by a hydraulic overpressure valve with an electronic pressure monitoring.

All engine ancillaries were driven by external devices. The cooling system was equipped with an electrical heater and an external circulation pump, providing accurate control of water and oil temperature.

Boost was realized with the use of supercharging. Vane compressor was driven by external electrical motor governed by pressure controller. 
The research engine was coupled to a DC current dynamometer, which allowed for motored engine operation. View of the engine test setup is shown in Fig. 1.

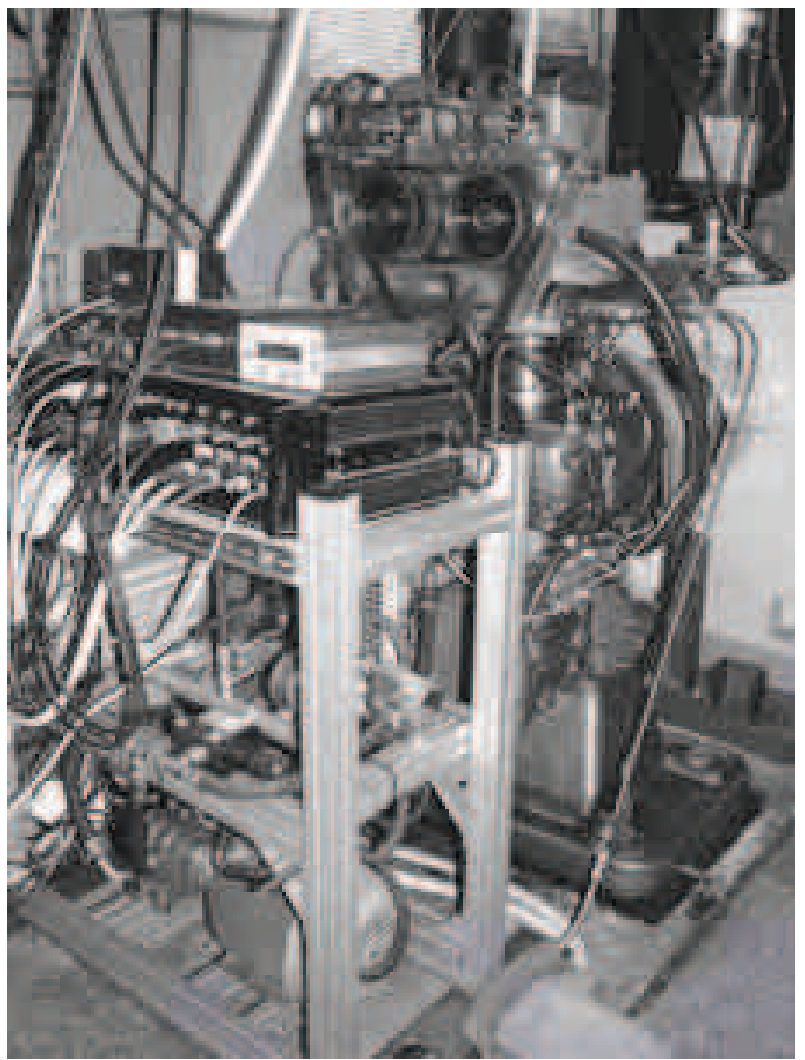

Fig. 1. Experimental test stand

The engine control system was based on a microprocessor timing module governed by a personal computer with real-time software. A dedicated injection and ignition timing module was designed in order to allow accurate and repeatable dosing of fuel and spark discharge generation. So as to avoid control errors resulting from engine rotational speed fluctuations, crankshaft angle domain procedures (injection and ignition timing) were controlled on the base of signals from the crankshaft encoder with angular resolution of $0.1^{\circ} \mathrm{CA}$. The same timing signal was used for triggering of the $\mathrm{A} / \mathrm{D}$ converter for the recording of the in-cylinder pressure and other signals acquired in the crankshaft angle domain.

\section{Research conditions and procedure}

The examinations were carried out at constant rotational speed equal $1500 \mathrm{rev} / \mathrm{min}$ and wide open throttle. The engine was fuelled with gasoline $(95 \mathrm{RON})$ from a single batch. Fuel pressure measured in a fuel rail was equal $10 \mathrm{MPa}$. Valves lifts were reduced to $3.6 \mathrm{~mm}$ for inlet valve and $2.9 \mathrm{~mm}$ for exhaust valve in order to realize NVO. At naturally aspirated operation four valvetrain settings were applied, providing variable NVO and resulting EGR rate. At boosted operation one valvetrain setting was used, while variable intake pressure and fuel dose were applied. In all experiments fuel was injected during NVO, however start of injection angle was varied in order to obtain stable engine operation.

Mass of trapped exhaust gases was calculated using gas state equation on the base of volume, pressure and temperature at exhaust valve closing. In order to avoid errors in the measured pressure signal due to vibrations at exhaust valve closing, pressure at EVC was calculated with the use of a recompression model obtained by fitting the measured pressure with a polytropic curve. 
Exhaust temperature was provided by a thermocouple located in the exhaust port close to the valve. EGR rate was calculated as a fraction of re-circulated exhaust mass and fresh intake air mass. The intake air mass was measured with the use of a mass flow meter. Fuel consumption was measured via a fuel balance with a measurement time of $30 \mathrm{~s}$. The indicated mean effective pressure (IMEP), heat release rate and mass fraction burnt were calculated on the basis of incylinder pressure traces.

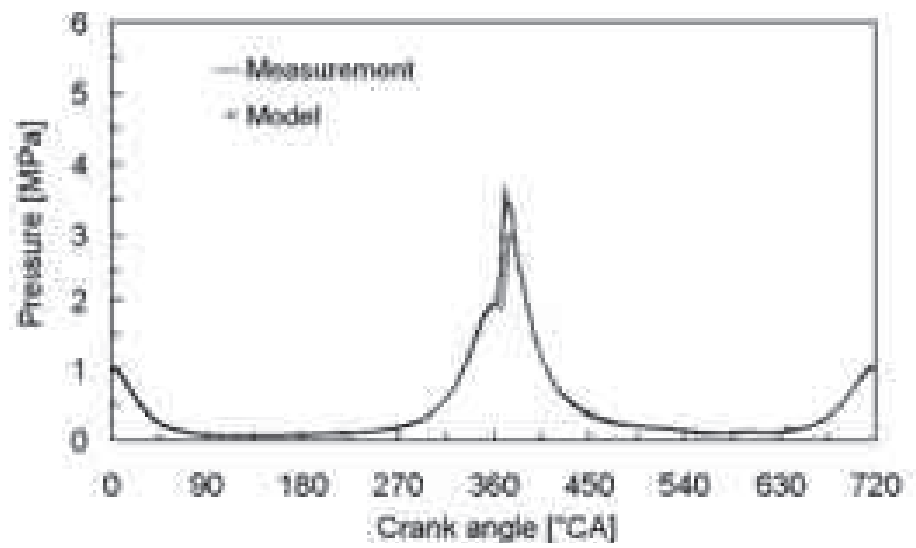

Fig. 2. In-cylinder pressure measured for several cycles and calculated with the use of the model at naturally aspirated operation, IMEP $=0.34 \mathrm{MPa}$

Experimental results have shown that at naturally aspirated operation start of compression temperature was constant and independent of valvetrain settings nor air excess ratio $(\lambda)$. However, calculation of temperature on the basis of in cylinder pressure, especially at low pressure values, can lead to estimation errors. Thus, experiments were complemented by zero-dimensional modelling of the engine cycle. Boost software from AVL was used for simulation. Calculations were done at the same conditions as during experiments. Furthermore, valvetrains settings, at which engine operation was not attainable were applied in order to verify reasons for operation boundary. Fig. 2 presents an example of measured and calculated in-cylinder pressure traces. The curves of HRR were introduced into the model on the base of thermodynamic experimental data analysis.

\section{Results at naturally aspirated operation}

Figure 3 presents attainable operation range of the engine at naturally aspirated conditions and variable valves timings and fuelling. Boundaries of EGR rate and air excess ratio $(\lambda)$ result from mixture composition and its thermodynamic properties. Maximum amount of trapped residuals is limited by the content of water and carbon dioxide. However, increase of air excess ratio results in a decrease of concentrations of mentioned exhaust components. Thus, the leaner mixture, the higher amount of residuals can be trapped. The minimum EGR rate results from necessity of heat introduction into combustion chamber, which limits amount of air in the cylinder and attainable engine load. The lowest engine load was achieved at the level of 0.15 $\mathrm{MPa}$ of IMEP and was limited by admissible mixture dilution and coefficient of variation (CoV) in IMEP, as shown in Fig. 4.

Figure 5 presents crank angle at 5\% mass fraction burnt (MFB). The earliest start of combustion was observed at slightly lean mixture and moderate EGR rate. Both increase and decrease of amount of trapped residuals resulted in combustion retard. This behavior was ascribed to thermal balance during intake process. Increase of trapped residuals resulted in decrease of exhaust temperature, thus enthalpy of mixture at the start of compression dropped. In contrast, at lower EGR rates provided higher temperature at the start of intake, however increasing of amount of intake air cooled down the mixture. 


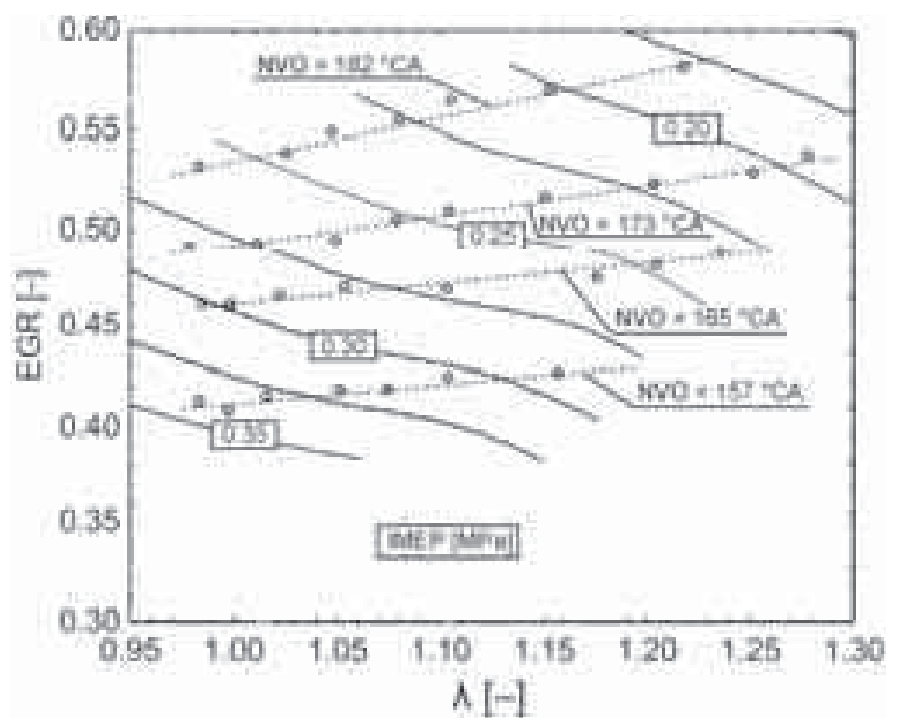

Fig. 3. Indicated mean effective pressure (IMEP) versus air excess ratio ( $\lambda$ ) and EGR rate; naturally aspirated operation

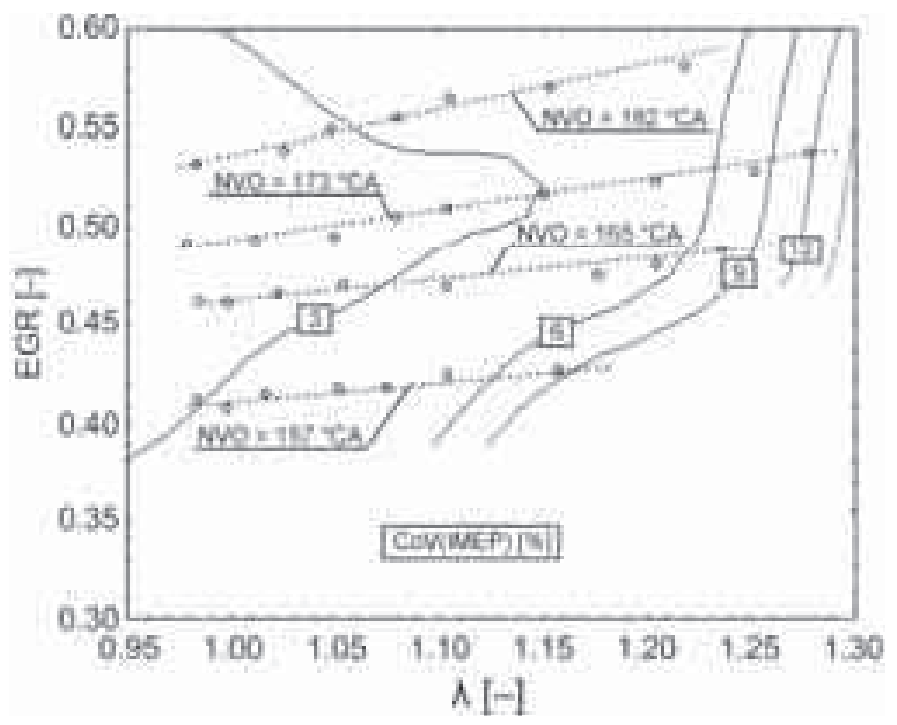

Fig. 4. Coefficient of variation (CoV) in IMEP versus air excess ratio ( $\lambda$ ) and EGR rate; naturally aspirated operation

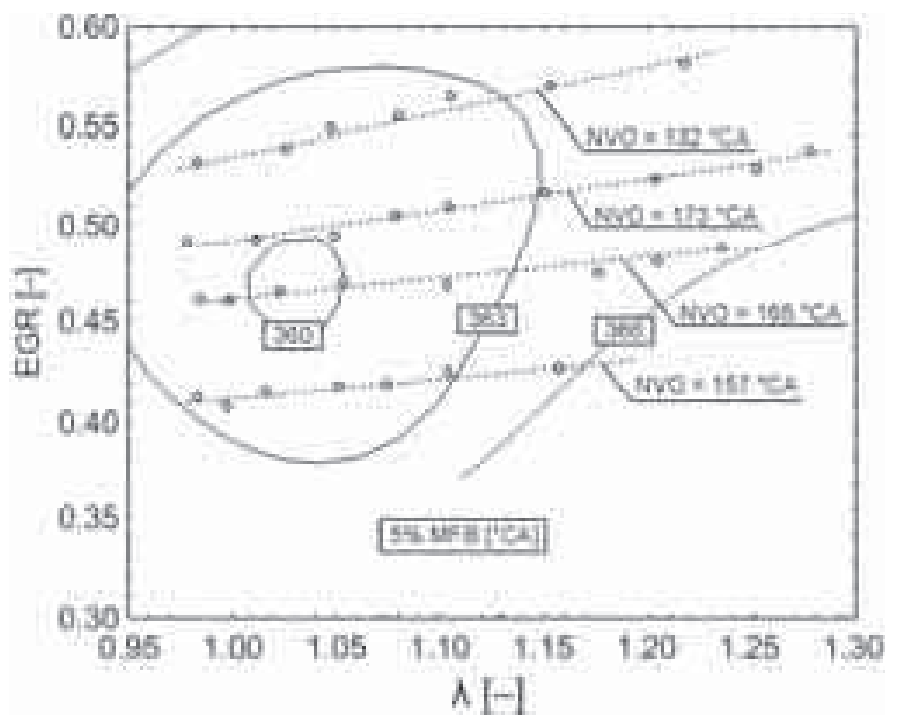

Fig. 5. Crank angle at 5\% of mass fraction burnt (MFB) versus air excess ratio ( $\lambda$ ) and EGR rate; naturally aspirated operation 
These phenomena were explained with the use of the engine cycle model. Temperature at IVC event was the highest at the range of EGR and air excess ratio where the earliest auto-ignition was observed. However, it should be noted that changes of IVC temperature are relatively small, as shown in Fig. 6. Modeling results showed the reasons for reduction of applicable air excess ratio at larger and smaller NVO crank angles. At extreme valvetrain settings allowing engine operation (NVO angles $182^{\circ} \mathrm{CA}$ and $157^{\circ} \mathrm{CA}$ ) and lean air-fuel mixture a drop of IVC temperature was observed. Calculations at reduced NVO crank angle (below values applied during experiments) showed reduction of IVC temperature, which results with disability of realizing autonomous engine operation in the HCCI mode.

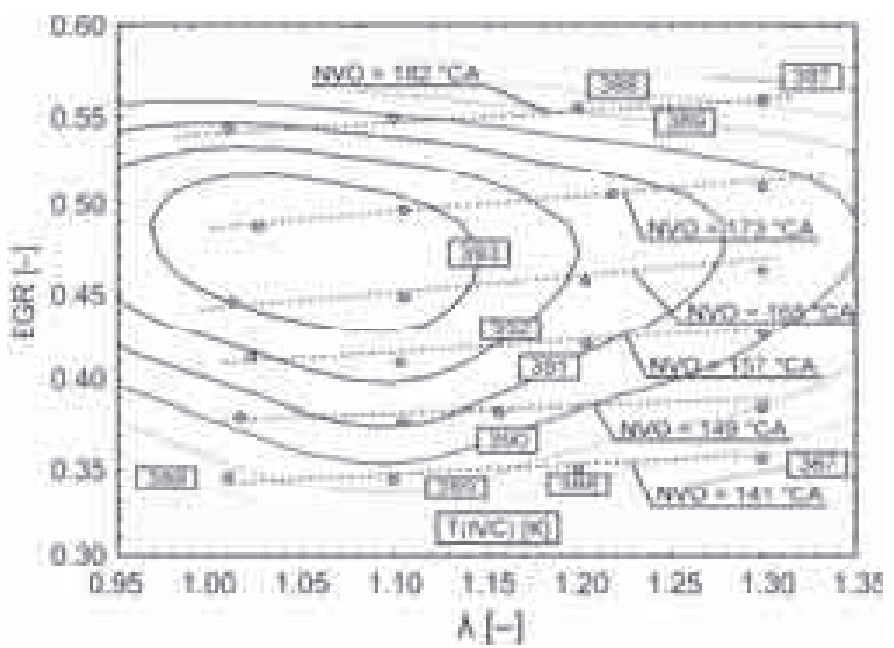

Fig. 6. Calculated temperature at intake valve closing (IVC) versus air excess ratio ( $\lambda$ ) and EGR rate; naturally aspirated operation

It should be noted that load exchange is a key process which enable operation of HCCI engine with internal gas re-circulation. In a whole attainable range of operation a balance between thermodynamic parameters of intake air and trapped residuals takes place. Volumetric efficiency, EGR rate and air excess ratio are strongly related. Also, entire in-cylinder mass in the whole range of engine operation was kept at constant level.

\section{Results at boosted operation}

Considering the fact that the highest achievable engine loads are limited by necessary amount of trapped residuals and resulting drop in terms of volumetric efficiency, in order to increase mass of intake air mechanical boost was applied. In this experiment at constant fuel doses intake pressure was varied from atmospheric or value providing stoichiometric mixture to $0.15 \mathrm{MPa}$. Increase of intake pressure allowed for obtaining IMEP at level of $0.6 \mathrm{MPa}$, as shown in Fig. 7 , versus $0.35 \mathrm{MPa}$ at ambient pressure (Fig. 3).

Experimental measurements and calculations showed that increase of intake pressure, apart from increase of fresh air in the cylinder, reduces the EGR rate. Considering changes in values of fresh air mass, exhaust mass and exhaust temperature, it was expected that boost application will result in drop of start of compression temperature and auto-ignition retard. However, experimental results provided relationships opposite to expected ones, as shown in Fig. 8. As a result of auto-ignition advance at higher boost pressure values, maximum pressure rise rate at higher load exceeded $1 \mathrm{MPa} /{ }^{\circ} \mathrm{CA}$. Thus, high engine loads were limited by admissible engine noise and harshness. The calculation results, shown in Fig. 9, confirmed relationship between intake pressure and start of compression temperature observed on the base of experimental data. At increasing amount of fresh air temperature at IVO is dropping, while temperature at IVC is rising. These temperature changes result from compression of the mixture during intake process. 


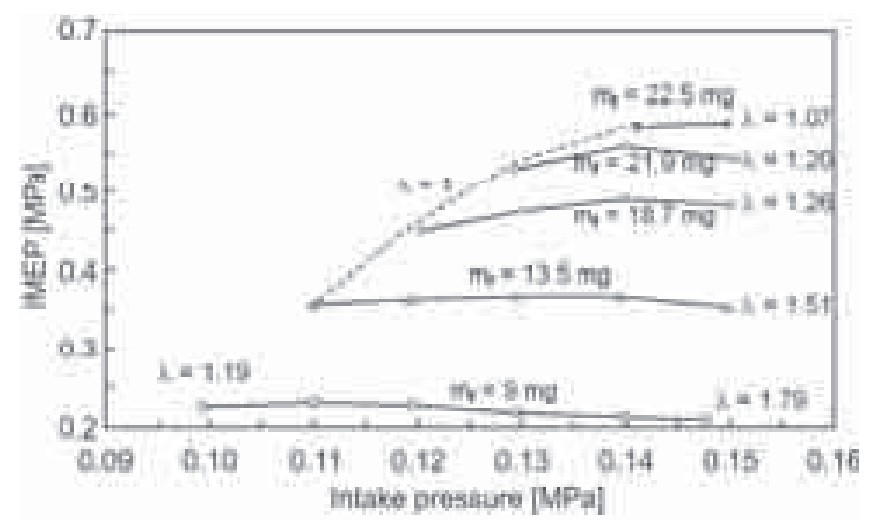

Fig. 7. Indicated mean effective pressure (IMEP) versus intake pressure at variable mass of fuel $\left(m_{f}\right)$ injected; $N V O=157^{\circ} \mathrm{CA}$

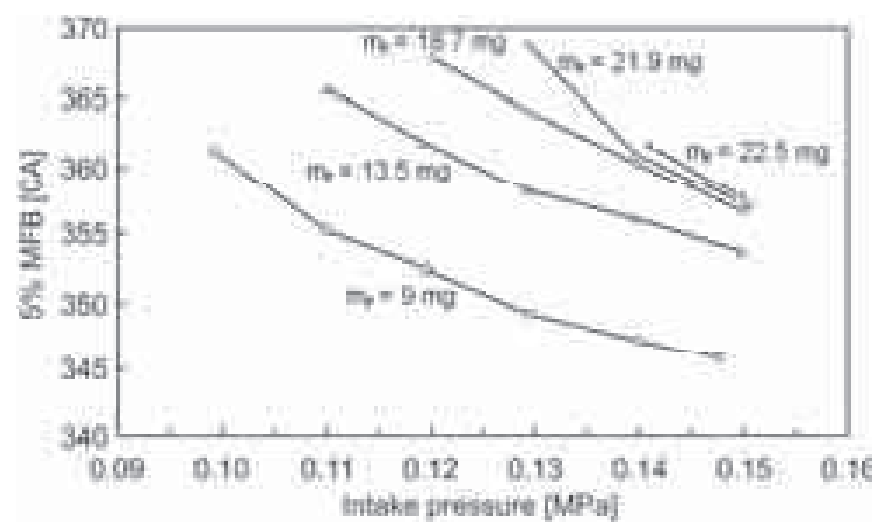

Fig. 8. Crank angle at $5 \%$ of mass fraction burnt (MFB) versus intake pressure at variable mass of fuel $\left(m_{f}\right)$ injected; $\mathrm{NVO}=157^{\circ} \mathrm{CA}$

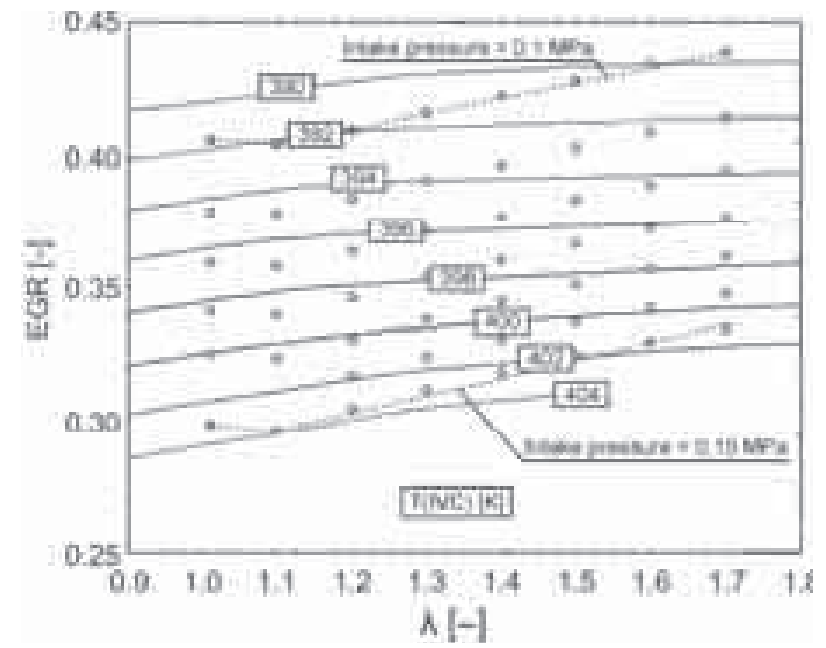

Fig. 9. Calculated temperature at intake valve closing (IVC) versus air excess ratio $(\lambda)$ and EGR rate at variable intake pressure; $\mathrm{NVO}=157^{\circ} \mathrm{CA}$

\section{Conclusions}

Results of experiments and modeling of the mechanically boosted HCCI gasoline engine with negative valve overlap were presented in this study. Research at naturally aspirated operation have shown that attainable engine loads are below $0.4 \mathrm{MPa}$ of IMEP. The boost application enabled extension of high load regime up to IMEP value of $0.6 \mathrm{MPa}$.

The findings of this study are summarized below:

1. Attainable range of the naturally aspirated engine operation is limited by the mixture 
temperature at the end of intake. Temperature at intake valve closing is less affected by air excess ratio than negative valve overlap crank angle. Thus, further increasing of volumetric efficiency via variable valves timings was not possible due to drop of temperature.

2. Increase of intake pressure allowed to achieve an improvement in terms of volumetric efficiency without the drop of start of compression temperature. The higher the intake pressure, the higher temperature and lower EGR rate were observed.

3. Application of boost results in advance of auto-ignition. At high mass of fuel injected, early auto-ignition increases the pressure rise rate. Thus, research into heat release rate control via variable injection timing or split fuel injection technique is necessary.

\section{Acknowledgements}

The authors wish to thank AVL List GmbH for making simulation software available within a framework of AVL University Partnership Program.

\section{References}

[1] Gaynor, J. A., Fleck, R., Kee, R. J., Kenny, R. G., Cathcart, G., A study of efficiency and emissions for a 4-Stroke SI and a CAI engine with EEGR and light boost, SAE Technical Paper 2006-32-0042, 2006.

[2] Hunicz, J., Kordos, P., An experimental study of fuel injection strategies in CAI gasoline engine, Experimental Thermal and Fluid Science, Vol. 35, pp. 243-252, 2011.

[3] Najt, P., Foster, D. E., Compression-Ignited Homogeneous Charge Combustion, SAE Technical Paper 830264, 1983.

[4] Scaringe, R. J., Wildman, C., Cheng, W. K., On the high load limit of boosted gasoline HCCI engine operating in NVO mode, SAE Technical Paper 2010-01-0162, 2010.

[5] Stanglmaier, R. H., Roberts, Ch. E., Homogeneous charge compression ignition (HCCI): benefits, compromises, and future engine applications, SAE Technical Paper 1999-01-3682, 1999.

[6] Wildman, C., Scaringe, R. J., Cheng, W. K., On the maximum pressure rise rate in boosted HCCI operation, SAE Technical Paper 2009-01-2727, 2009.

[7] Yao, M., Zheng, Z., Liu, H., Progress and recent trends in homogeneous charge compression ignition (HCCI) engines, Progress in Energy and Combustion Science, Vol. 35, pp. 398-437, 2009.

[8] Yap, D., Wyszyński, M. L., Megaritis, A., Xu, H., Applying boosting to gasoline HCCI operation with residual gas trapping, SAE Technical Paper 2005-01-2121, 2005. 